\title{
Imaging of upper crustal structure beneath East Java-Bali, Indonesia with ambient noise tomography
}

\author{
Agustya Adi Martha ${ }^{1,2^{*}}$, Phil Cummins ${ }^{3}$, Erdinc Saygin ${ }^{4}$, Sri Widiyantoro ${ }^{5,6}$ and Masturyono ${ }^{2}$
}

\begin{abstract}
The complex geological structures in East Java and Bali provide important opportunities for natural resource exploitation, but also harbor perils associated with natural disasters. Such a condition makes the East Java region an important area for exploration of the subsurface seismic wave velocity structure, especially in its upper crust. We employed the ambient noise tomography method to image the upper crustal structure under this study area. We used seismic data recorded at 24 seismographs of BMKG spread over East Java and Bali. In addition, we installed 28 portable seismographs in East Java from April 2013 to January 2014 for 2-8 weeks, and we installed an additional 28 seismographs simultaneously throughout East Java from August 2015 to April 2016. We constructed inter-station Rayleigh wave Green's functions through cross-correlations of the vertical component of seismic noise recordings at 1500 pairs of stations. We used the Neighborhood Algorithm to construct depth profiles of shear wave velocity (Vs). The main result obtained from this study is the thickness of sediment cover. East Java's southern mountain zone is dominated by higher $\mathrm{Vs}$, the Kendeng basin in the center is dominated by very low Vs, and the Rembang zone (to the North of Kendeng zone) is associated with medium Vs. The existence of structures with oil and gas potential in the Kendeng and Rembang zones can be identified by low Vs.
\end{abstract}

Keywords: Ambient noise tomography, East Java, Cross-correlation, Neighborhood Algorithm, Sediment

\section{Background}

The eastern part of Java is an area with complex geology. Physiographically (Fig. 10b), the study area is divided into six zones: (a) quaternary volcanoes, (b) alluvial plains of Northern Java, (c) Rembang-Madura anticlinorium, (d) Bogor, North Serayu, and Kendeng anticlinorium, (e) central depression zone of Java and Randublatung, and (f) Southern Mountains (Bemmelen 1949). Based on structure and stratigraphy, the eastern part of Java is divided into four tectonostratigraphic zones from south to north: the Southern Mountains zone, present-day volcanic arc, Kendeng zone, and Rembang zone. Based on the character of its bedrock, the eastern part of Java is

\footnotetext{
${ }^{*}$ Correspondence: agustyaadi@gmail.com

${ }^{1}$ Study Program of Earth Sciences, Faculty of Earth Science

and Technology, Institut Teknologi Bandung, Jalan Ganesa No. 10,

Bandung 40132, Indonesia

Full list of author information is available at the end of the article
}

divided into three zones, i.e., the Southern Mountains, Kendeng, and Rembang zones (Smyth et al. 2005). Since it is the character of the bedrock that appears to be best reflected in our tomography results, we mainly focus on this characterization in our interpretation of the results.

The Southern Mountains, Kendeng, and Rembang zones have characteristics that are quite striking. The Southern Mountains zone on land in the southern part of the research area has a positive gravity anomaly that is quite high. The Kendeng zone which is located in the north part of the Southern Mountains zone has a negative Bouguer anomaly, and the Rembang zone which is located in the northern area of the Kendeng zone has a positive Bouguer anomaly. These Bouguer anomalies are associated with the condition of the lithosphere and the depth of bedrock in each zone.

To image the subsurface structure of the research area, we used ambient noise tomography (ANT), a geophysical 
method that is often used to estimate subsurface seismic velocity structure and particularly the thickness of sediment (Lin et al. 2007). ANT has been used previously at several locations in Indonesia, including Lake Toba (Stankiewcs et al. 2010), Central Java (Zulfakriza et al. 2014), the Jakarta Basin (Saygin et al. 2016), the western part of East Java (Martha et al. 2015), and East Java and Bali (Martha et al. 2016).

We followed the steps taken by Saygin and Kennett (2012) in processing of the ambient seismic noise signal data to obtain maps of Rayleigh wave group velocity. The group velocity dispersion curves obtained from these maps at each point in a regular grid covering the study area were inverted to obtain Vs-depth profiles using the Neighborhood Algorithm (NA) (Sambridge 1999a, b).

\section{Data and method}

Data

In this paper, we used seismic waveform data recorded by 24 seismograph stations operated by BMKG and 28 portable seismographs installed independently for 14-60 days in 2014. The seismographic sensors that we used in this research were Trillium Compact $20 \mathrm{~s}$, Lennartz 3D Lite, BBVS, CMG-3T, and STS-2. Noise recorded by these stations was used to image the group velocity under the research area (Martha et al. 2016). We further installed 28 seismographs from August 2015 until April 2016, which were used to increase the inter-station path coverage and thereby obtain better imaging results. The interstation distances range from $\sim 5$ to $\sim 400 \mathrm{~km}$.

Figure 1 illustrates the distribution of seismographic station locations in the research area. It includes some

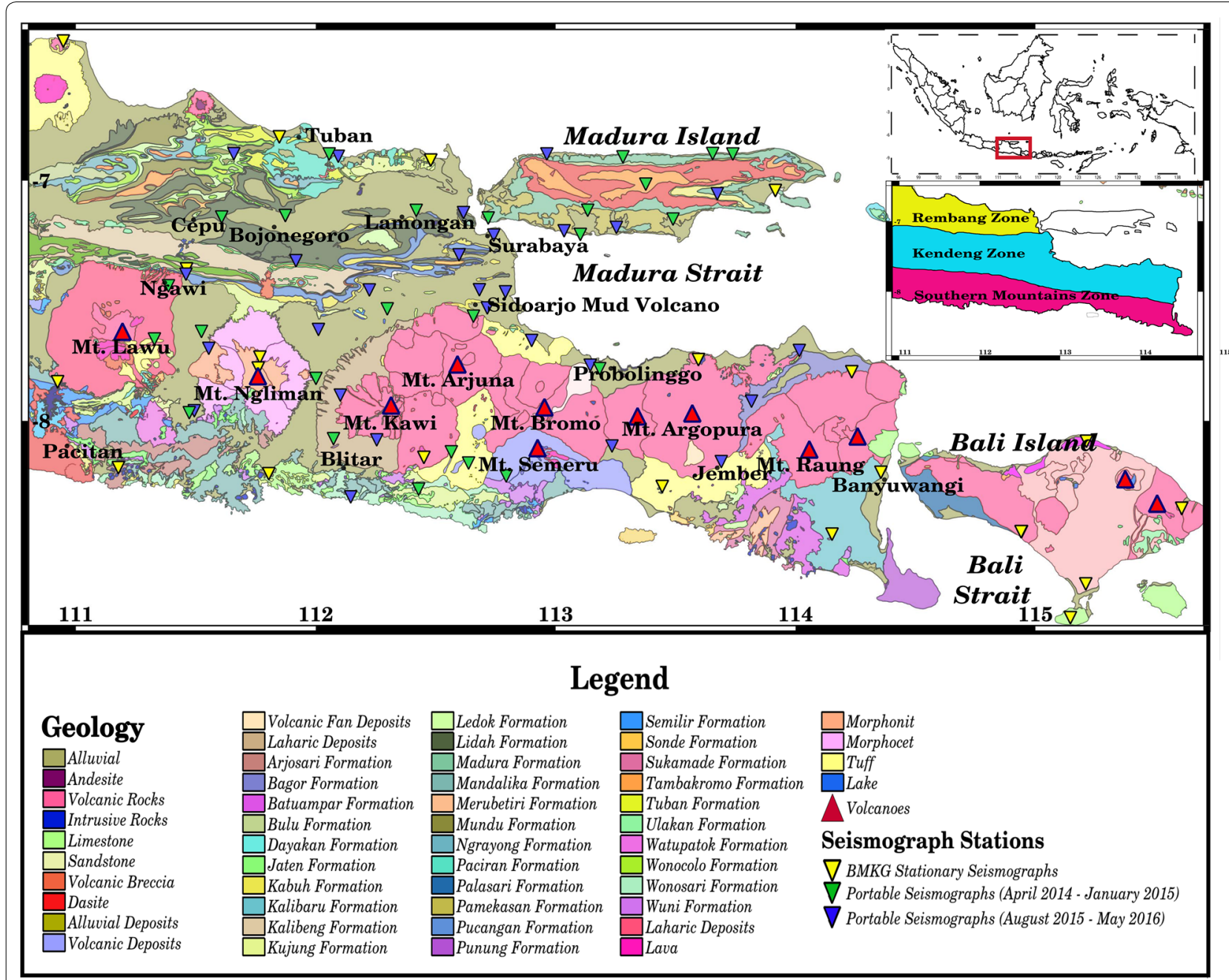

Fig. 1 Map of seismographic stations used in this research overlaid on a geological map [modified from Gafoer and Ratman (1999); Purbo-Hadiwidjoyo et al. (1998)]. The crustal character [modified from Smyth et al. (2008)] and the approximate location (red square) of the research are shown in the inset map 
regions of Central Java, East Java, and Bali. The seismograph sensors used in this research are of various types, so we removed the instrument response in each seismogram. The vertical component seismograms obtained following instrument removal were used to construct Rayleigh wave Green's functions.

\section{Ambient noise correlation}

Cross-correlation of noise on the surface of the earth began to be developed by Rickett and Claerbout (1999), the results of this study presented in helioseismology. Lobkis and Weaver (2001) and Weaver and Lobkis (2001) demonstrated in laboratory experiments. Ritzwoller et al. (2002) Comparing group-velocity charts of calculation periods from cross-correlation of two different seismograph stations with the predicted dispersion curve of ray-tracing in the structure of ballistic surface waves (Shapiro and Campillo 2004). Campillo and Paul (2003), Shapiro and Campillo (2004), and Sabra et al. (2005) demonstrated empirical cross-correlation calculations of seismic noise wavefield recorded on two seismographs.

Sabra et al. (2005) constructed the time derivative of the ambient noise cross-correlation $C_{i j}(1,2, t)$ between two different seismograph stations, station 1 (located at $r_{1}$ recording component $i$ ) and station 2 (located at $r_{2}$ recording component $j$ ) to the time domain Green's function (TDGF) $G_{i j}\left(r_{1} ; r_{2}, t\right)$.

$$
\frac{\mathrm{d} C_{i j}}{\mathrm{~d} t} \approx-G_{i j}\left(r_{1} ; r_{2}, t\right)+G_{j i}\left(r_{2} ; r_{1},-t\right)
$$

The TDGF $G_{i j}\left(r_{1} ; r_{2}, t\right)$ relates a unit concentrated impulse displacement in direction $i$ at $r_{1}$ to the displacement response in direction $j$ at receiver $r_{2}$. The TDGF which comes from random noises that propagate from station 1 to 2 produces a positive correlation time delay $t$ and the time-reversed TDGF produces a negative correlation time delay $-t$ (Sabra et al. 2005).

Figure 2 shows the cross-correlation processing schemes in this research, for A and B pair stations. We obtained more than 1500 inter-station cross-correlations from the 2000 available station pairs (some were dropped because Rayleigh wave signals were not well represented in the cross-correlations). Figure 3 illustrates the results of cross-correlation between station PCJI and other stations, showing average Rayleigh wave group velocities of about $3 \mathrm{~km} / \mathrm{s}$. This relatively high velocity may be due to the area around PCJI being dominated by igneous rocks. The quality of Green's functions produced by the cross-correlations at each pair of seismographic stations depends on the time length of the waveform used, the condition of the subsurface structure surface waves have passed through, the distance between the stations in each pair, and the degree of human activity around the stations.

\section{Tomographic inversion}

The group velocities were generated from the Green's function results of cross-correlated time series in the research area using multiple filter technique (MFT) of Dziewomski et al. (1969). This research used fast marching surface tomography (FMST) scheme to obtain tomographic images, which was developed by Rawlinson (2005). FMST implements forward and inverse problems using fast marching method (FMM) (Sethian 1996; Sethian and Popovici 1999; Rawlinson and Sambridge 2005) and subspace (Kenneth et al. 1988), respectively.

Fast marching method constructs wave fronts from phase delays with eikonal equations using finite differences within predefined grids (Rawlinson and Sambridge 2005). Inversion subspace is used to obtain optimal modeling perturbation on each iteration (Kenneth et al. 1988).

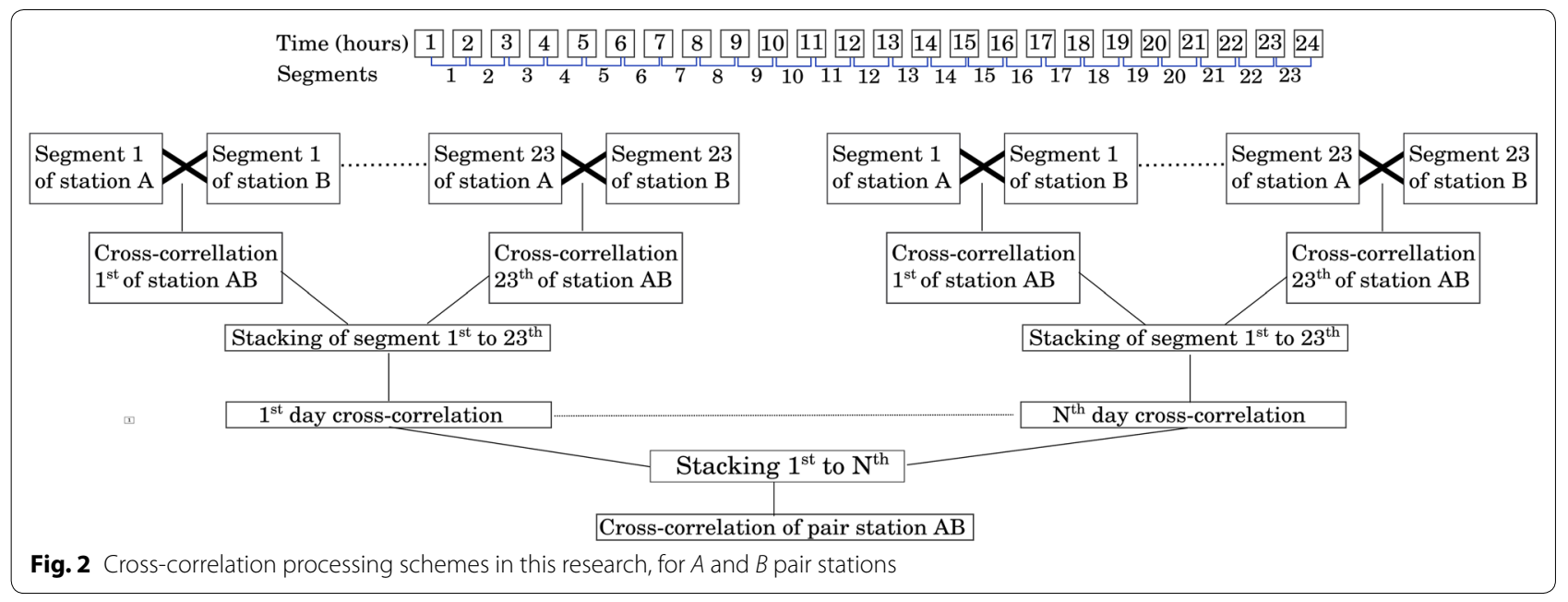




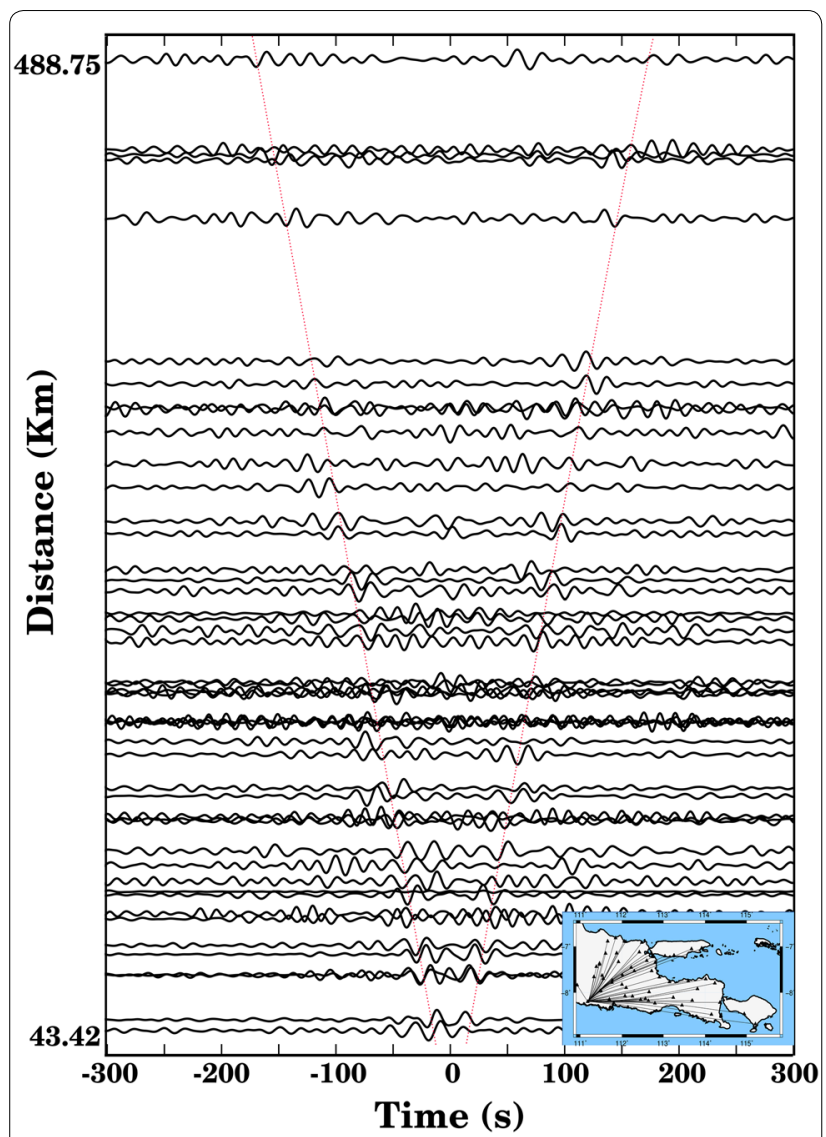

Fig. 3 Rayleigh wave Green's functions between a permanent station (PCJI) on the southwestern edge of the network and other stations. Waveforms were filtered between 0.08 and $0.3 \mathrm{~Hz}$. The time length of cross-correlation starts from 0 to $300 \mathrm{~s}$. Red lines show group velocities of $3 \mathrm{~km} / \mathrm{s}$

This inversion method follows a recurring linear schema, and ray paths are recalculated after each model update. The FMM and subspace combinations provide stable and robust results on highly diverse media (Rawlinson et al. 2010). The inversion allows smoothing and damping regulation to be used to solve non-uniqueness problems.

The inversion problem is formulated as an optimization problem where it is necessary to minimize the objective function $S(m)$ given by

$$
\begin{aligned}
S(m)= & \left(g(m)-d_{\mathrm{obs}}\right)^{\mathrm{T}} C_{\mathrm{d}}^{-1}\left(g(m)-d_{\mathrm{obs}}\right) \\
& +\varepsilon\left(m-m_{0}\right)^{\mathrm{T}} C_{\mathrm{m}}^{-1}\left(m-m_{0}\right)+\eta m^{\mathrm{T}} D^{\mathrm{T}} D m,
\end{aligned}
$$

where $m$ is the unknown vector of the model parameter, $\mathrm{d}_{\text {obs }}$ represent the data of group delay observation, $g(m)$ contains the prediction of travel time, $m_{0}$ is the reference model, $C_{\mathrm{d}}$ represent the data of covariance matrix, $C_{\mathrm{m}}$ is the model of covariance matrix, $\varepsilon$ is the damping variable, $\eta$ is the smoothing variable, and $D$ is the smoothness matrix.

\section{Results and discussion Checkerboard test}

Several "checkerboard tests" have been conducted to ascertain the resolution of the Rayleigh wave group velocity maps produced in the tomographic inversion for each period. These tests have been conducted using the configuration of ray paths from the source to the receiver that resulted from the seismometer deployments described above.

Figure 4 shows the results of checkerboard tests at different periods using a grid size of $0.25^{\circ} \times 0.25^{\circ}$, approximately $27.8 \mathrm{~km} \times 27.8 \mathrm{~km}$ with a maximum velocity perturbation of $1 \mathrm{~km} / \mathrm{s}$. We selected values for the damping and smoothing parameters from a range of 500-5000 to obtain the optimum values and found the optimum values of 1800 and 1800, respectively. The results indicate that the southeastern portion of the research area is not as well resolved as the other areas, so we expect that the results of the tomographic inversion may not recover the details of Rayleigh wave group velocities in this area well.

\section{Group velocity}

The ray path distributions associated with the group velocity models resulting from our tomographic inversions for different periods are shown in Fig. 5 . There are various numbers of ray paths at different periods, due to the decreasing number of available station pairs for long periods and the decreasing signal-to-noise ratio at short periods. Figure 4 shows that the ray paths exhibit pronounced bending due to the strong variations in group velocity. The ANT inversion results (Fig. 6) illustrate the variation of Rayleigh wave group velocity beneath the surface of the research area in the period range from 0.8 to $12 \mathrm{~s}$. They show a strong contrast between group velocities of the Southern Mountains zone and those of the Kendeng and Rembang zones. The Southern Mountain zone, which is associated with intrusive Oligo-Miocene age volcanic rocks and middle Miocene carbonates, is dominated by relatively high group velocity $(1.8-3.2 \mathrm{~km} / \mathrm{s})$. The Kendeng zone, which is composed of sedimentary basin fill, is dominated by very low group velocity $(0.2-1 \mathrm{~km} / \mathrm{s})$. The Rembang zone, which is associated with modern volcanic and alluvial deposits and carbonate rocks, is dominated by medium group velocity $(1-1.8 \mathrm{~km} / \mathrm{s})$, but its most northern part is associated with middle Miocene carbonates having higher Vs (1.8$2.5 \mathrm{~km} / \mathrm{s}$ ). Bali Island, which is associated with modern volcanics, was dominated by high group velocity, but the southwestern part of Bali, which is associated with 


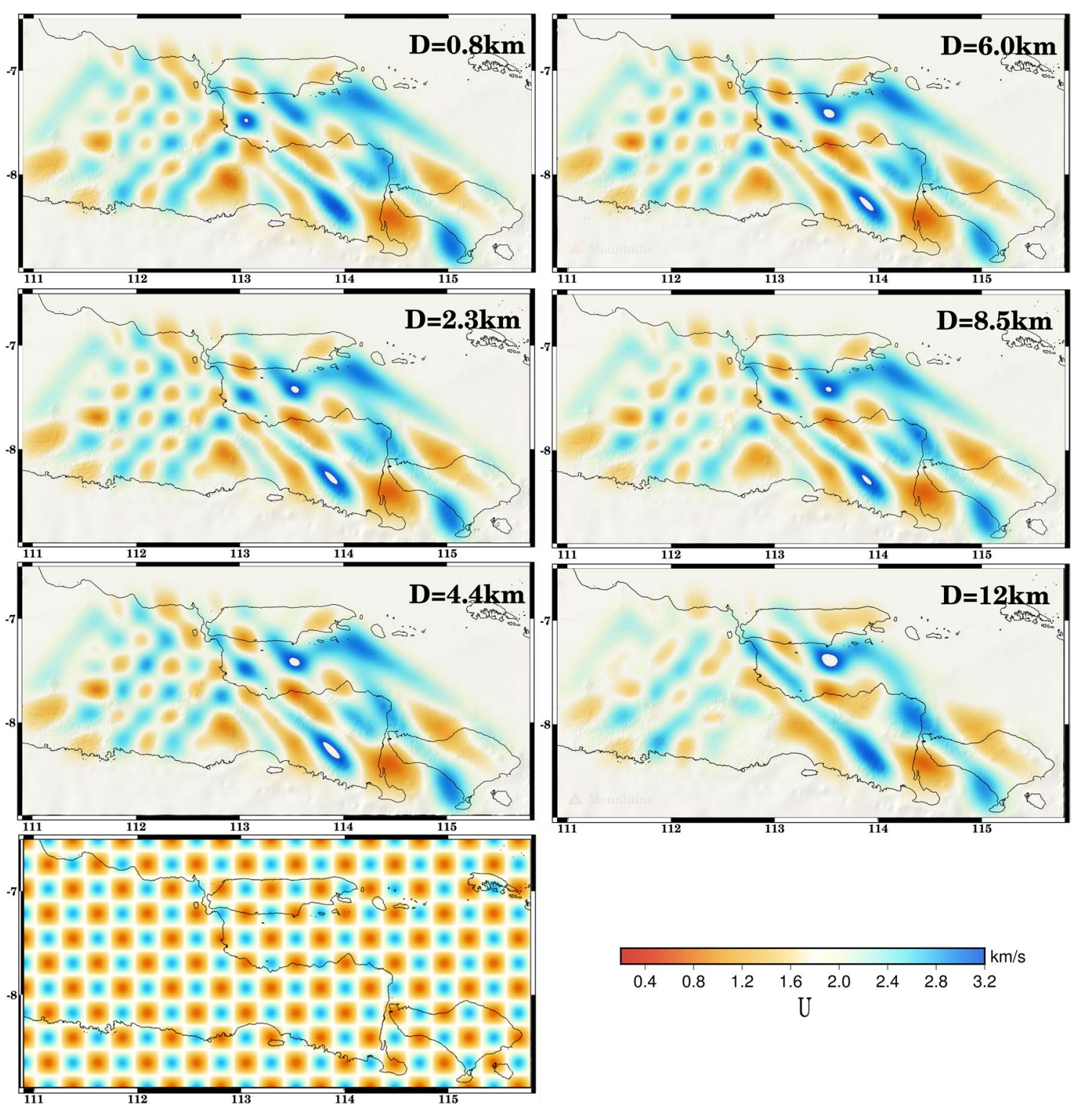

Fig. 4 Checkerboard test using damping and smoothing factors of 1800 and 1800, respectively

modern volcanic and alluvial deposits, is dominated by low group velocity.

\section{Inversion of group velocity curves}

In this work, we used the Neighborhood Algorithm (NA) developed by Sambridge (1999a, b), to invert the ANT group velocity dispersion curves for Vs-depth profiles at each point in a regular grid covering the study area. Using a grid spacing of $0.125^{\circ}$, we took 469 sample points of group velocity results in the period range from 0.5 to $12.2 \mathrm{~s}$ in the research area. The dispersion curve at each of these points was inverted to obtain the profile of Vs as a function of depth.

Figure 7 shows two examples of dispersion curve inversions using the NA. Points 33, 139, and 226 are located at the Rembang, Kendeng, and Southern Mountains zones, respectively. The red curves indicate the $1 \mathrm{D}$ Vs-depth profiles corresponding to the minimum misfit among the models sampled by NA at each point. As expected, point 226 in the Southern Mountains zone has generally higher shear wave velocity than points 33 and 139 in the Rembang and Kendeng Zone, respectively. 


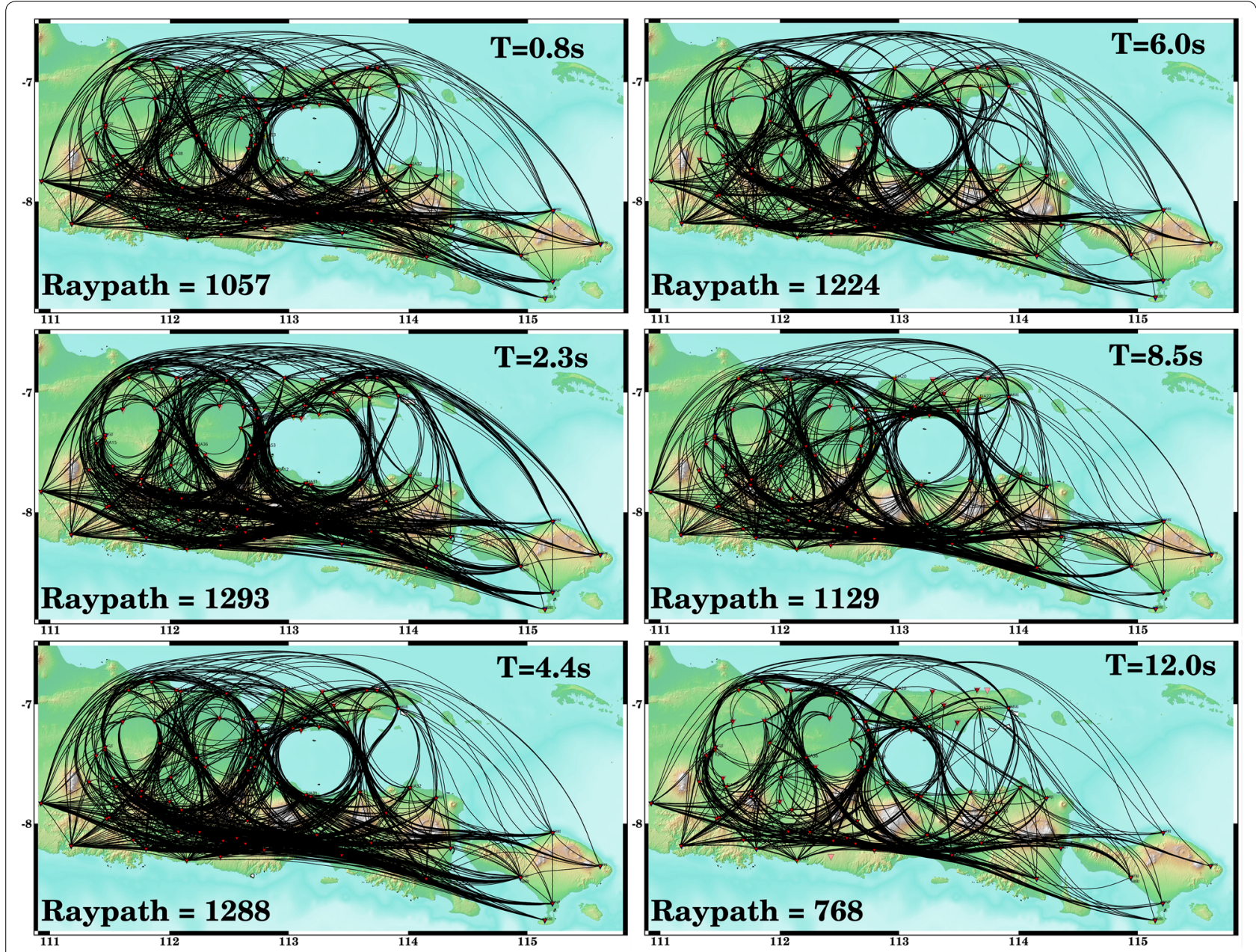

Fig. 5 Ray path distribution at selected periods using damping and smoothing factors of 1800 and 1800, respectively. The histogram shows the distribution of the ray path number

Figure 8 shows the NA inversion results for shear wave velocity throughout the study area, which included the Southern Mountains, Kendeng, and Rembang zones (Fig. 1). The Southern Mountains Zone is dominated by high shear wave velocity. Velocities of $2.0-3.1 \mathrm{~km} / \mathrm{s}$ are evident at depths as shallow as $0.8 \mathrm{~km}$, and this indicates that the bedrock is fairly shallow in this zone. The tomography results show that the boundary zone between the Southern Mountains zone and Kendeng zone is clearly defined. There is a continuous low-velocity anomaly to the north that merges with the Kendeng zone in the depth range of $0.8-4.4 \mathrm{~km}$ in the southern part of the study area. The highest Vs are to the south of the arc of active volcanoes. In general, the deeper the higher velocity extends, the clearer it can be seen in the Vs maps.
The tomographic image of the Kendeng zone is dominated by a strong low-velocity anomaly. This result indicates that this area is an area with thick sedimentary basin fill. The lowest velocity can be seen in Ngawi, Lamongan, Madura Sea, and Bojonegoro, where velocities as low as $1 \mathrm{~km} / \mathrm{s}$ extend to depths as great as $6.0 \mathrm{~km}$. The location of the mud volcano disaster in Sidoarjo was associated with $\mathrm{Vs}<1.0 \mathrm{~km} / \mathrm{s}$ ranging from 0.8 to $4.4 \mathrm{~km}$ depth.

The shear wave velocity structure of the Rembang Zone is characterized by moderate Vs on average, but it includes relatively high Vs in the southern part of this zone and middle part of Madura Island. These regions are areas of limestone excavation at the surface so that its appearance is that of high cliffs. In the Bojonegoro and Cepu regions, which are well known for exploitation 


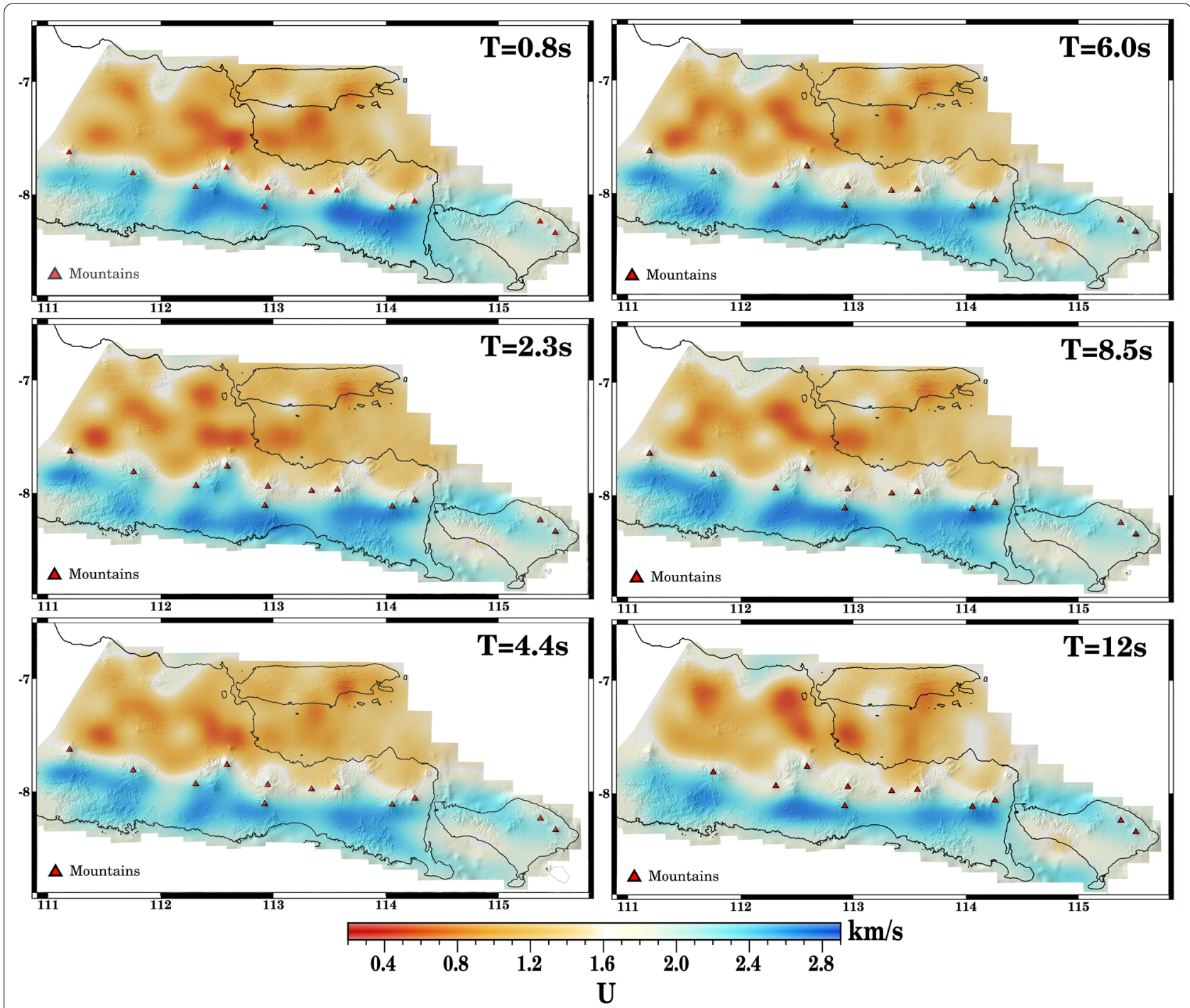

Fig. 6 Rayleigh wave group velocity tomograms from subspace inversion of ambient noise tomography data between 0.8 and $12.0 \mathrm{~s}$

of oil and gas, the results are dominated by low-Vs anomalies.

\section{Cross-sections}

Figure 9 shows the variation of Vs in W-E (West-East) cross-sectional images across the study area. Cross-section 1 transects the Rembang zone which has varying sediment thickness. The imaging results of the Vs structure beneath cross-section 1 shows low (Vs $<2.0 \mathrm{~km} / \mathrm{s}$ ) velocity throughout the upper crust, but particularly in its central portion, where Vs below $1.0 \mathrm{~km} / \mathrm{s}$ extends to depths $>10 \mathrm{~km}$.
Cross-section 2 that cuts W-E through land to the Madura Sea is in the Kendeng zone. The Vs structure under cross-section 2 also exhibits low (Vs $<2.0 \mathrm{~km} / \mathrm{s}$ ) velocity throughout the upper crust. There is a pronounced low-velocity zone beneath the Sidoarjo mud volcano at $112.50^{\circ}-112.75^{\circ}$ longitude that extends from the surface to about $4 \mathrm{~km}$ depth which may be related to the source of the massive mud eruption that has been ongoing there since 2006.

Cross-section 3 is another W-E section in the Southern Mountains zone. This cross-section shows that this entire zone is underlain by relatively normal crustal 

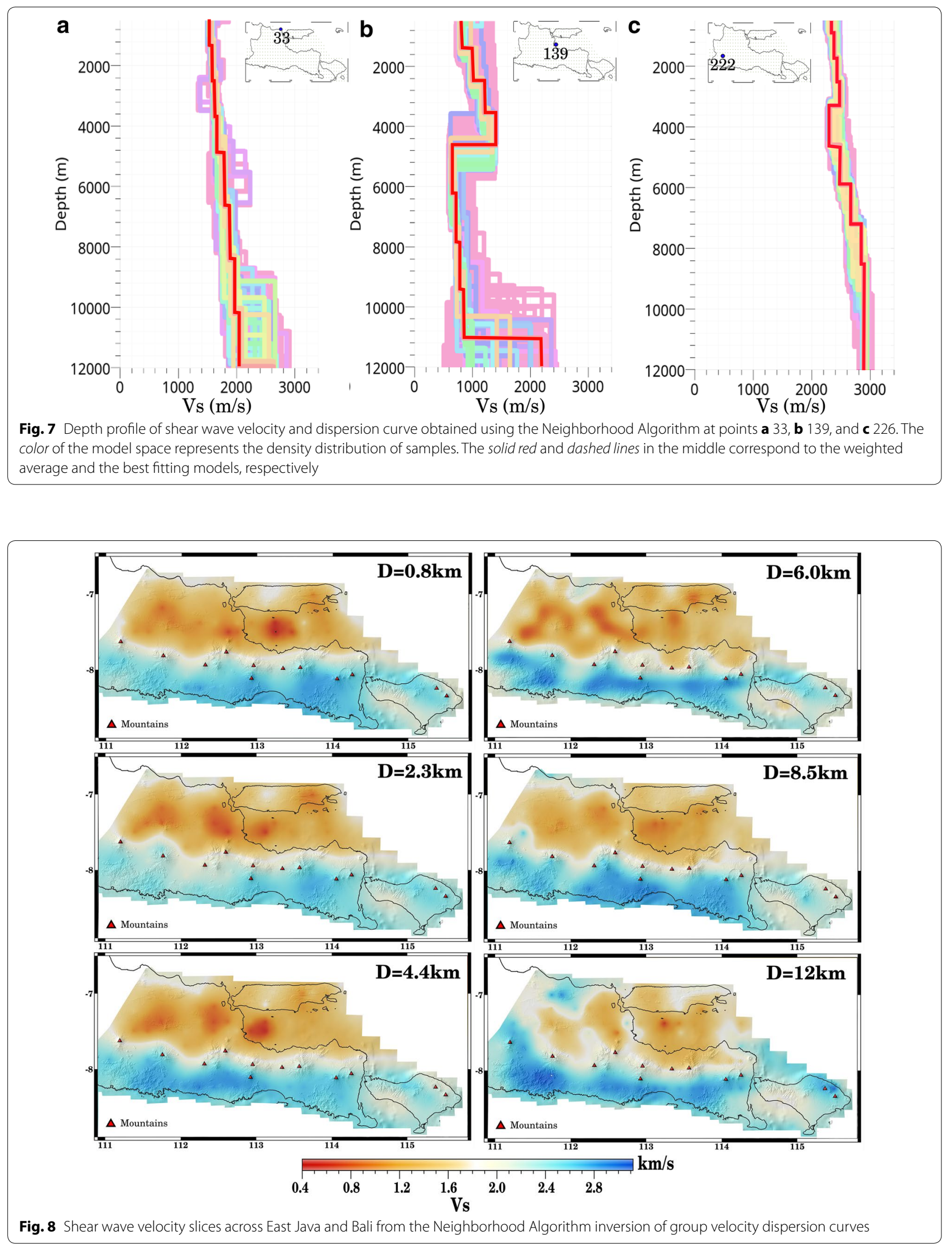


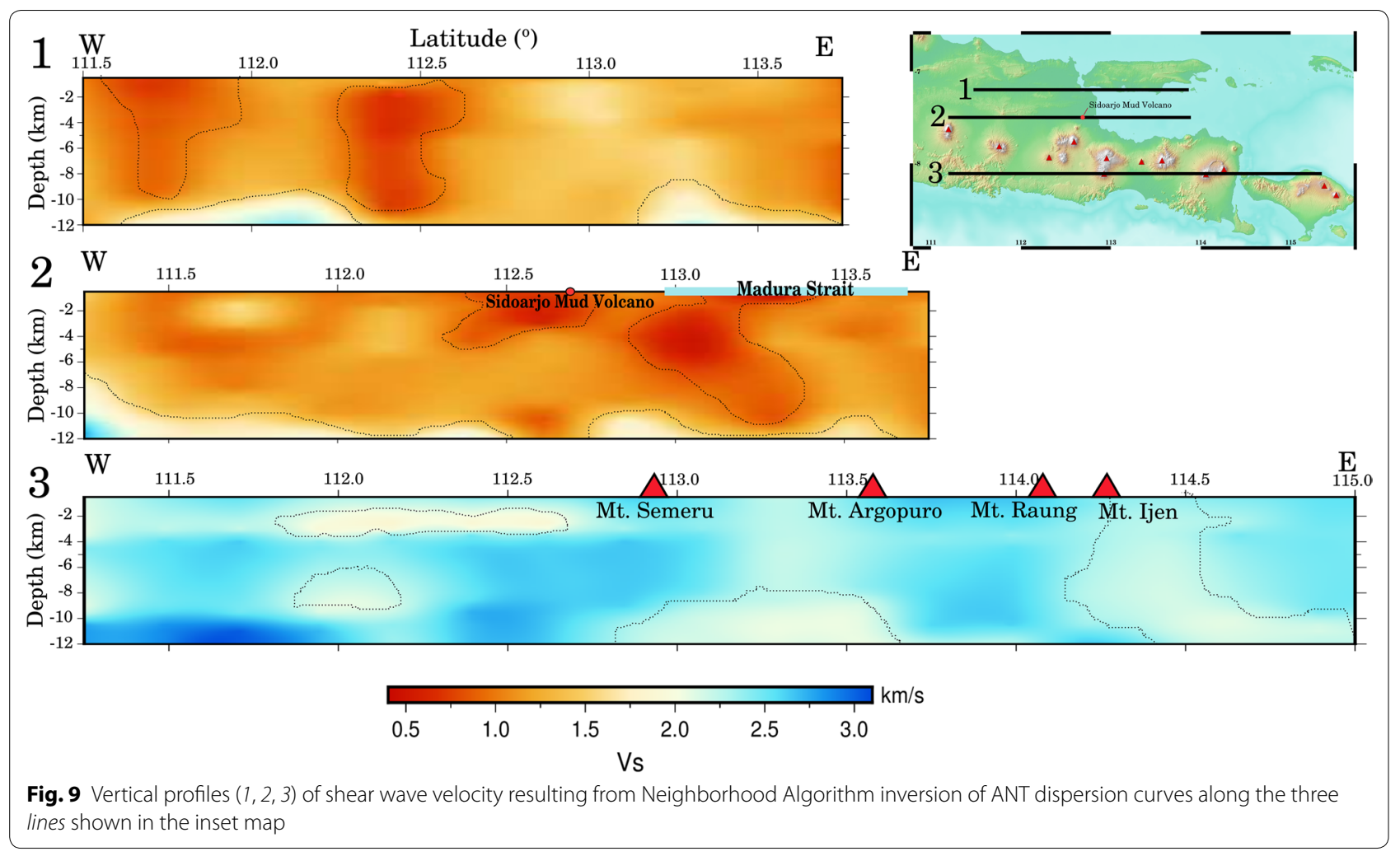

velocities of $1.8-3.1 \mathrm{~km} / \mathrm{s}$. Cross-section 3 crosses several volcanoes, including Semeru, Argopuro, Raung, and Ijen mountains. On this cross-section, the existence of volcanoes seems correlated with relatively low velocity. This could be caused the age of these volcanic rocks is younger than that of the southern part of volcanoes.

The cross-sections in Fig. 10 are in the S-N (SouthNorth) direction and cuts through the three different zones. These cross-sections show the boundary of the three zones-Rembang, Kendeng, and Southern Mountains-very clearly. Cross-sections 4-6 are all dominated by higher shear wave velocities $(2-3.0 \mathrm{~km} / \mathrm{s})$ at the Southern, lower shear wave velocity $(0.4-1.5 \mathrm{~km} / \mathrm{s})$ in the middle and intermediate $(1.5-3 \mathrm{~km} / \mathrm{s})$ in the northern part of the cross-sections. Cross-sections 4 and 5 show that the Kendeng Basin depth is in the range of $10-11 \mathrm{~km}$.

\section{Comparison of results with geology and oil and gas fields}

The comparison between imaging results of this research and of previous research (Fig. 11) shows correlations of the Vs structure with surface geology and oil and gas fields. In the Southern Mountains zone, which was dominated by high Vs, high Bouguer anomalies correlate with the presence of igneous and carbonate rocks. The very low average Vs in the upper crust of the Kendeng zone correlates well with low Bouguer anomalies and the presence of basins and thick sedimentation. The Madura Sea, which is also dominated by very low Vs, also correlates with very low Bouguer anomalies. The middle part of Madura Island, which is dominated by medium shear wave velocity, corresponds to a medium Bouguer anomaly. The low Vs in the Rembang and Kendeng zones also correlate well with the existence of oil and gas fields. Relatively high Vs beneath the southern part of Bali Island, on the other hand, correlate with a high Bouguer anomaly.

\section{Conclusions}

Seismic ambient noise tomography by cross-correlation of seismic ambient noise using seismographic data of BMKG as well as data from several portable seismograph deployments describes the condition of the subsurface structure of the eastern Java-Bali region. Low shear wave velocity is associated with basins and sedimentary layers, 


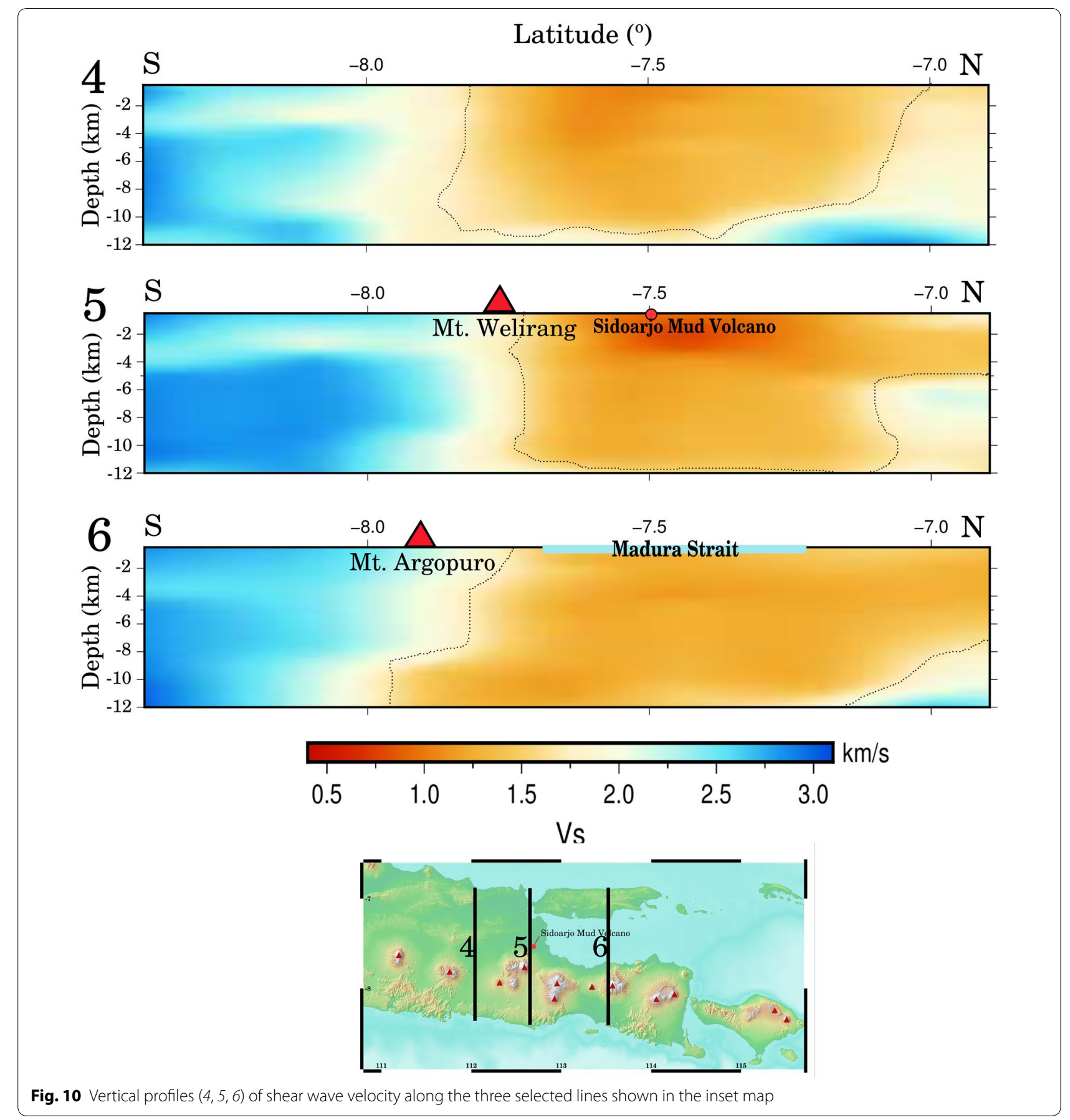

while high-velocity anomaly is associated with igneous rocks and carbonates. The Kendeng basin thickness reaches $8-10 \mathrm{~km}$, but the Madura Sea has even thicker sediment. The Kendeng and Southern Mountains zones are bounded by active volcanoes. The existences of volcanoes in the eastern Java region are associated with moderately low-velocity structures. The results of tomographic imaging indicate a correlation with the results 

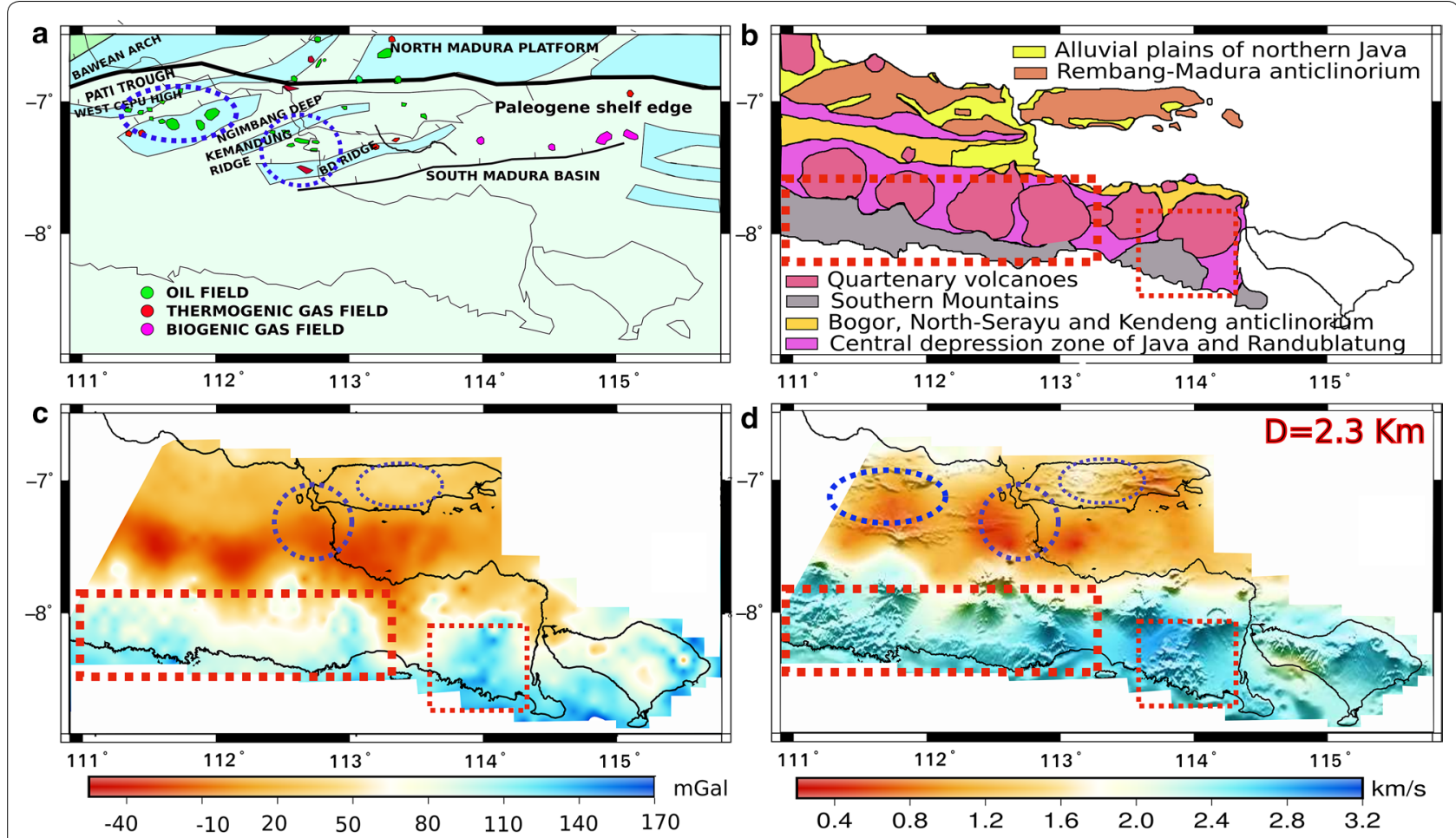

Fig. 11 a Paleogene paleogeography of East Java basin [modified from Satyana and Purwaningsih (2002)]. b Physiography map [modified from Bemmelen (1949)]. c Bouguer Anomaly of East Java and Bali area. d Shear wave velocity at $2.3 \mathrm{~km}$ depth. Shapes (squares and circles) indicate the similarity of structure

of previous studies (geology, physiography, and Bouguer anomalies). The presence of oil and gas fields in this research area correlates well with low-velocity anomalies.

\begin{abstract}
Abbreviations
ANT: ambient noise tomography; BMKG: Badan Meteorologi, Klimatologi, dan Geofisika/Bureau of meteorological, climatological and geophysics; Vs: shear wave velocity; NA: Neighborhood Algorithm; km: kilometer; TDGF: time domain Green's function; MFT: multiple filter technique; FMST: fast marching surface tomography; FMM: fast marching method; $\mathrm{km} / \mathrm{s}$ : kilometer/second; 1D: 1 dimension; W-E: west-east; S-N: south-north; Mt: mountain; s: second; D: depth; T: period; m/s: meter/second; mGal: miliGal.
\end{abstract}

\section{Authors' contributions}

Study conception and design, acquisition of data, and critical version: AAM, PC, ES, SW, and M. Analysis and interpretation of data: AAM. Manuscript drafting: AAM, PC, and SW. All authors read and approved the final manuscript.

\section{Author details}

${ }^{1}$ Study Program of Earth Sciences, Faculty of Earth Science and Technology, Institut Teknologi Bandung, Jalan Ganesa No. 10, Bandung 40132, Indonesia. ${ }^{2}$ Agency for Meteorology, Climatology and Geophysics (BMKG), Jakarta, Indonesia. ${ }^{3}$ Research School of Earth Sciences, Australian National University, Canberra, ACT 2601, Australia. ${ }^{4}$ Centre for Energy Geoscience, School of Earth Sciences, University of Western Australia, Perth, Australia. ${ }^{5}$ Global Geophysics Research Group, Faculty of Mining and Petroleum Engineering, Institut Teknologi Bandung, Jalan Ganesa No. 10, Bandung 40132, Indonesia. ${ }^{6}$ Research Centre for Disaster Mitigation, Institut Teknologi Bandung, Jalan Ganesa No. 10, Bandung 40132, Indonesia.

\section{Acknowledgements}

Agustya Adi Martha is very grateful to the Ministry of Research, Technology and Higher Education, Republic of Indonesia, for the doctoral scholarship given to him. The data used in this study were taken from BMKG and portable seismometers installed independently with the help of funding from the Australian Department of Foreign Affairs and Trade Grant 71982. We used Generic Mapping Tools (Wessel and Smith 1998) to draft Figs. (4, 5, 6, 8, 9, 10, and $11 c, d)$.

\section{Competing interests}

We declare that we have no significant competing financial, professional, or personal interests that might have influenced the performance or presentation of the work described in this manuscript.

\section{Availability of data and materials}

We used data from the seismographic stations operated by BMKG. For portable seismographic data, we are in the process of preparing several manuscripts using the data set. We will share the data soon after the manuscripts are published.

\section{Funding}

The data used in this study were taken from BMKG (Free) and portable seismometers installed independently by the help of funding from the Australian Department of Foreign Affairs and Trade Grant 71982.

\section{Publisher's Note}

Springer Nature remains neutral with regard to jurisdictional claims in published maps and institutional affiliations.

Received: 9 February 2017 Accepted: 6 June 2017

Published online: 19 June 2017 


\section{References}

Bemmelen RWV (1949) The Geology of Indonesia. Government Printing Office, The Hague

Campillo M, Paul A (2003) Long-range correlations in the diffuse seismic coda. Science 299:547-549

Dziewonski A, Bloch S, Landisman M (1969) A technique for analysis of transient seismic signal. Bull Seismol Soc Am 59:427-444

Gafoer S, Ratman N (1999) Peta Geologi Regional Jawa Bagian Timur, Skala 1:500.000. Pusat Penelitian dan Pengembangan Geologi, Bandung

Kenneth BLN, Sambridge MS, Williamson PR (1988) Subspace methods for large scale inverse problems involving multiple parameter classes. Geophys I 94:237-247

Lin FC, Ritzwoller MH, Townend J, Bannister S, Savage MK (2007) Ambient noise Rayleigh wave tomography of New Zealand. Geophys J Int 170:649-666

Lobkis Ol, Weaver RL (2001) On the emergence of the Green's function in the correlations of a diffuse field. J Acoust Soc Am 110:3011-3017

Martha AA, Widiyantoro S, Cummins PR, Saygin E, Masturyono (2015) Upper crustal structure beneath East Java from ambient noise tomography: a preliminary result. AIP Conf Proc 1658:030009

Martha AA, Widiyantoro S, Cummins PR, Saygin E, Masturyono (2016) Investigation of upper crustal structure beneath Eastern Java. AIP Conf Proc 1730:020011

Purbo-Hadiwidjoyo MM, Samudro H, Amin TC (1998) Peta Geologi Lembar Bali, Nusatenggara, Skala 1:250.000. Pusat Penelitian dan Pengembangan Geologi, Bandung

Rawlinson N (2005) FMST: fast marching surface tomography package. Research School of Earth Sciences, Australian National University, Canberra, p 0200

Rawlinson N, Sambridge M (2005) The fast marching method: an effective tool for tomographic imaging and tracking multiple phases in complex layered media. Expl Geophys 36:341-350

Rawlinson N, Pozgay S, Fishwick S (2010) Seismic tomography: a window into deep Earth. Geoscience. doi:10.1016/j.pepi.2009.10.002

Rickett J, Claerbout J (1999) Acoustic daylight imaging via spectral factorization: helioseismology and reservoir monitoring. Lead Edge 18:957

Ritzwoller MH, Shapiro NM, Barmin MP, Levshin AL (2002) Global surface wave diffraction tomography. J Geophys Res 107(B12):2335. doi:10.1029/200 2JB001777

Sabra K, Gerstoft P, Roux P, Kuperman WA, Fehler MC (2005) Extracting timedomain Green's function estimates from ambient seismic noise. Geophys Res Lett 32(3):1-5
Sambridge M (1999a) Geophysical inversion with a neighborhood algorithm I: searching a parameter space. Geophys J Int 138:479-494

Sambridge M (1999b) Geophysical inversion with a neighborhood algorithm II: appraising the ensemble. Geophys I Int 138:727-746

Satyana AH, Purwaningsih MEM (2002) Geochemistry and habitats of oil and gas in the East Java Basin: regional evaluation and new observations. In: Proceedings of the 31st IPA annual convention. pp 68-102

Saygin E, Kennett BLN (2012) Crustal structure of Australia from ambient seismic noise tomography, J Gephys Res 117(B1)

Saygin E, Cummins PR, Cipta A, Hawkins R, Pandhu R, Murjaya J, Masturyono, Irsyam M, Widiyantoro S, Kennett BLN (2016) Imaging architecture of the Jakarta Basin, Indonesia with transdimensional inversion of seismic noise. Geophys J Int 204(2):918-931

Sethian JA (1996) A fast marching level set method for monotonically advancing fronts. Proc Natl Acad Sci 93:1591-1595

Sethian JA, Popovici AM (1999) 3-D traveltime computation using the fast marching method. Geophysics 64:516-523

Shapiro NM, Campillo M (2004) Emergence of broadband Rayleigh waves from correlations of the ambient seismic noise. Geophys Res Lett 31(7):1615-1619

Smyth H, Hall R, Hamilton J, Kinny P (2005) East Java: cenozoic basins, volcanoes and ancient basement. In: Proceeding of the 30th IPA annual convention, vol 258. Jakarta, pp 269-282

Smyth H, Hall R, Nichols GJ (2008) Cenozoic volcanic arc history of East Java, Indonesia: the stratigraphic record of eruptions on an active continental margin. Geol Soc Am Spec Pap 436:200-224

Stankiewcs J, Ryberg T, Haberland C, Fauzi, Natawidjaja D (2010) Lake Toba volcano magma chamber imaged by ambient seismic noise tomography Geophys Res Let 37:L17306. doi:10.1029/2010GL044211

Weaver RL, Lobkis OI (2001) Ultrasonics without a source: thermal fluctuation correlations at MHz frequencies. Phys Rev Lett 87:134301. doi:10.1103/ PhysRevLett.87.134301

Wessel P, Smith WH (1998) New improved version of generic mapping tools released. EOS Trans Am Geophys Union 79:579

Zulfakriza Z, Saygin E, Cummins PR, Widiyantoro S, Nugraha AD, Lühr BG, Bodin T (2014) Upper crustal structure of central Java, Indonesia, from transdimensional seismic ambient noise tomography. Geophys J Int 197:630-635

\section{Submit your manuscript to a SpringerOpen ${ }^{\circ}$ journal and benefit from:}

- Convenient online submission

- Rigorous peer review

- Open access: articles freely available online

- High visibility within the field

- Retaining the copyright to your article

Submit your next manuscript at $\boldsymbol{\nabla}$ springeropen.com 